\title{
Pathogenicity of capsulate and non-capsulate members of Bacteroides fragilis and $B$. melaninogenicus groups in mixed infection with Escherichia coli and Streptococcus pyogenes.
}

\section{BROOK}

Departments of Pediatrics and Surgery, Uniformed Services University of the Health Sciences, Bethesda, MD 20814-5145, USA

\begin{abstract}
Summary. The relationships between capsulate and non-capsulate Bacteroides fragilis strains and Escherichia coli, and between capsulate and non-capsulate strains of the B. melaninogenicus group and Streptococcus pyogenes, were studied in a subcutaneous abscess model in mice. Selective antimicrobial agents directed against either aerobic or anaerobic bacteria were used alone or in combination to explore the effect of eradication of one component of the mixed infection. Single agent therapy effective against both aerobic and anaerobic flora was also employed. Single therapy of mixed infection directed at the elimination of only one organism $(S$. pyogenes, $E$. coli or Bacteroides sp.) caused significant reductions in the numbers of sensitive organisms and also smaller yet significant decreases in the numbers of insensitive organisms. However, the abscesses were not eliminated after such therapy. Combination therapy or use of a single agent (cefoxitin) directed against the aerobic and anaerobic components of the infection was more effective. Non-capsulate Bacteroides spp. became capsulate after passage in mice mixed with either $S$. pyogenes or $E$. coli. Therapy directed at the elimination of $S$. pyogenes and $E$. coli did not prevent the emergence of capsulate Bacteroides spp. These data demonstrate the synergy between all members of the $B$. fragilis group and $E$. coli and between the $B$. melaninogenicus group and $S$. pyogenes, and reiterate the need to direct antimicrobial therapy at the eradication of the aerobic and anaerobic components of mixed infections.
\end{abstract}

\section{Introduction}

Members of the Bacteroides fragilis group mixed with Escherichia coli are often isolated from intraabdominal infections (Brook, 1988), while members of the B. melaninogenicus group and Streptococcus pyogenes are frequently isolated from orofacial and respiratory infections (Brook, 1981). Although the virulence of capsulate strains of $B$. fragilis is well established (Onderdonk et al., 1977; Brook et al., $1984 a, b)$ the pathogenicity of other members of the $B$. fragilis and $B$. melaninogenicus groups requires further investigation.

We have previously demonstrated the ability of "helper" organisms to assist in the emergence of capsulate Bacteroides spp. in vivo (Brook et al., 1983,

Received 8 Feb. 1988; accepted 19 April 1988.

Offprint requests should be sent to Dr I. Brook, Armed Forces Radiobiology Research Institute, Bethesda, MD 20814-5145, USA. 1984a). However, since this phenomenon depended on the presence of viable "helper" bacteria, it was important to ascertain whether elimination of these bacteria by selective antibacterial agents would interfere with the production of capsulate Bacteroides spp. and the formation of abscesses.

In this study, the relationship between capsulate and non-capsulate members of the $B$. fragilis group and $E$. coli, and between capsulate and noncapsulate strains of the $B$. melaninogenicus group and $S$. pyogenes was studied in experimental subcutaneous abscesses in mice. Selective antimicrobial agents directed against either aerobic or anaerobic bacteria were used alone or in combination to explore the effect of eradication of one component of the mixed infection. This model enabled study of the interactions between the organism and also the effect of antimicrobials on the process of capsulation of the Bacteroides spp. 


\section{Materials and methods}

\section{Organisms}

All aerobic and anaerobic bacterial strains used in the experiments were recent clinical isolates. They included one strain each of $B$. fragilis, $B$. thetaiotaomicron, $B$. vulgatus, $B$. melaninogenicus, $B$. asaccharolyticus, $B$. intermedius, $E$. coli, and $S$. pyogenes. The bacteria were kept frozen in skim milk at $-70^{\circ} \mathrm{C}$. They were identified by standard criteria (Lennette et al., 1985; Sutter et al., 1985 ) and processed as previously described (Brook et al., 1983). Each species of Bacteroides contained two forms: one non-capsulate $(<0.1 \%$ of the organisms had a capsule) and the other capsulate ( $>50 \%$ of the organisms had a capsule). The capsulate form was induced by passage of the non-capsulate form mixed with Klebsiella pneumoniae in subcutaneous (s.c.) abscesses in mice (Brook et al., 1983). The presence of a capsule was established by Hiss's staining method (Lennette et al., 1985) and confirmed by electronmicroscopy after staining with ruthenium red (Kasper, 1976). Ruthenium red staining demonstrated a homogeneous polysaccharide capsule external to the cell wall. Capsular stains revealed the presence of a capsule also in $S$. pyogenes.

Frozen bacterial suspensions were thawed to room temperature, subcultured on to Schaedler blood agar, and incubated for $48 \mathrm{~h}$ at $37^{\circ} \mathrm{C}$ in an anaerobic glove box (Sutter et al., 1985) for Bacteroides spp. or in $5 \% \mathrm{CO}_{2}$ for other bacteria; $24 \mathrm{~h}$ before injection into mice, the bacterial strains were inoculated on to Trypticase Soy Agar containing, sheep blood 5\% (BBL Microbiology Systems, Cockeysville, MD). Colonies were harvested with cotton swabs from these media and transferred to normal $(0.9 \%)$ saline. The suspensions of organisms prepared were equivalent to a $0.5 \mathrm{McF}$ arland standard. Viable counts (cfu) were determined by plate counts on brain-heart infusion agar enriched with vitamin $\mathrm{K}_{1}$ and haemin to support the growth of the Bacteroides spp.

\section{Animals}

The mice used were male Swiss albino mice, weighing 20-25 g, obtained from the Naval Medical Research Institute mouse colony. The mice were raised in conventional conditions. Each mouse was inoculated s.c. in the right groin with $0.1 \mathrm{ml}$ of each appropriate bacterial suspension, in saline, that contained $10^{8} \mathrm{cfu}$ of each organism. To induce a combined infection, two inocula were mixed and each animal received $0.2 \mathrm{ml}$ containing $0.1 \mathrm{ml}$ of each bacterial suspension.

\section{Cultivation of abscess contents}

Animals were killed by cervical dislocation on day 5 after injection of bacteria. The sizes of the abscesses were estimated from measurements by caliper of two perpendicular diameters, corresponding to maximum length and width. The product of these two measurements, expressed as $\mathrm{mm}^{2}$, was approximately proportional to the outer surface of the abscess. For the determination of the bacterial contents of the abscesses, the abscess material was removed aseptically and homogenised, in an anaerobic glove box, in $1 \mathrm{ml}$ of sterile saline in a ground-glass tissue homogeniser. Tenfold serial dilutions of the homogenates were made in sterile saline, and $0 \cdot 1$ ml volumes of each dilution were spread in triplicate on brain heart infusion enriched blood-agar plates. No attempt was made to inactivate the antimicrobial agents in the homogenised abscess material, since a considerable dilution was achieved before plating, especially with the smaller abscesses. Colonies were counted after incubation at $37^{\circ} \mathrm{C}$ in an anaerobic chamber for $48 \mathrm{~h}$, and the results are presented as $\log _{10}$ of viable bacteria (cfu) per abscess.

\section{Antimicrobial therapy}

Antimicrobial therapy was directed against either species or both species present in the abscess. Metronidazole was directed against the Bacteroides spp. only and gentamicin was directed against $E$. coli only, whereas spiramycin was directed against $S$. pyogenes.

Dosages of antimicrobial agents were selected on the basis of pharmacokinetic studies on untreated animals (table I). Serum levels of antibiotics were measured by agar diffusion assay (Lennette et al., 1985) at 30, 60, 120 and $180 \mathrm{~min}$ after administration of the last dose of the agents. Abscess levels were measured $1 \mathrm{~h}$ after administration of the last dose of antimicrobial agents on day 5 . In most instances, the doses of antimicrobial agents approximated (in $\mathrm{mg} / \mathrm{kg}$ ) to the usual recommended dose for human patients. The total dosages (in $\mathrm{mg} / \mathrm{kg}$ of body weight) administered intramuscularly (i.m.) at intervals of $8 \mathrm{~h}$ were: gentamicin (Schering, Kenilworth, $\mathrm{NJ}$ ) 7.5; metronidazole (Searle, Chicago, IL) 50; spiramycin (Rhone-Poulenc, SA, Paris) 100; and cefoxitin (Merck

Table I. Blood and abscess concentration of metronidazole, spiramycin, gentamicin and cefoxitin in mice infected with $B$. fragilis and $E$. coli (for metronidazole, gentamicin and cefoxitin) and B. melaninogenicus and $S$. pyogenes (for spiramycin)

\begin{tabular}{|c|c|c|c|}
\hline \multirow{2}{*}{$\begin{array}{l}\text { Antimicrobial agent } \\
\text { (Daily dose, } \mathrm{mg} / \mathrm{kg} \text { ) }\end{array}$} & \multicolumn{2}{|c|}{$\begin{array}{c}\text { Serum level } \\
\text { (mg/L)* } \\
\text { at }\end{array}$} & \multirow[t]{2}{*}{$\begin{array}{l}\text { Abscess } \\
\text { level (mg/ } \\
\text { L)* at } 1 \mathrm{~h}\end{array}$} \\
\hline & $0 ; 5 \mathrm{~h}$ & $8 \mathrm{~h}$ & \\
\hline \multirow{4}{*}{$\begin{array}{l}\text { Metronidazole } \\
(50) \\
\text { Spiramycin } \\
(100) \\
\text { Gentamicin } \\
(75) \\
\text { Cefoxitin } \\
(200)\end{array}$} & $27 \cdot 6(7 \cdot 1)$ & $11 \cdot 4(3 \cdot 1)$ & $13 \cdot 6(4 \cdot 1)$ \\
\hline & $8 \cdot 0(2 \cdot 5)$ & $1.8(0.8)$ & $6 \cdot 1(1 \cdot 3)$ \\
\hline & $6 \cdot 4(1 \cdot 6)$ & $1 \cdot 2(0 \cdot 5)$ & $3.9(1.6)$ \\
\hline & $56 \cdot 0(9 \cdot 1)$ & $18 \cdot 2(1 \cdot 8)$ & $12 \cdot 4(1 \cdot 2)$ \\
\hline
\end{tabular}

*Mean (SEM) of 10 determinations. 
Sharp and Dohme, West Point, PA) 200. Treatment was started $2 \mathrm{~h}$ after inoculation and continued for 5 days. The concentrations of metronidazole were assayed by high-performance liquid chromatography (Wheeler et al., 1978). The concentration of all other agents was determined by diffusion assays (Lennette et al., 1985); for spiramycin and cefoxitin with Micrococcus luteus ATCC 9341 and for gentamicin with Bacillus subtilis ATCC 6633 .

\section{Susceptibility tests}

The MICs of the test antibiotics against the bacterial isolates were determined by agar dilution (Thornsberry and Svenson, 1978; Lennette et al., 1985).

\section{Experimental design}

To determine relationships between the various organisms in mixed infections, non-capsulate and capsulate Bacteroides spp. were injected in combination with one species at a time: $B$. fragilis group with $E$. coli and $B$. melaninogenicus group with $S$. pyogenes.

A group of 32 mice was challenged with single species or mixtures of Bacteroides spp. with the facultative anaerobes. Each infected group was divided into four groups of eight mice and given no treatment (1), or therapy with single agents ( 2 and 3 ), or combination therapy (4). Each experiment was done three times. Statistical analysis was Student's $t$ test of independent means.

\section{Results}

\section{In-vitro susceptibility to antibiotics}

Members of the $B$. fragilis and B. melaninogenicus groups were susceptible to metronidazole (MIC $0 \cdot 1 \mathrm{mg} / \mathrm{L}$ ) and cefoxitin (MIC $<4 \mathrm{mg} / \mathrm{L}$ ) and were resistant to gentamicin (MIC $>256 \mathrm{mg} / \mathrm{L}$ ) and spiramycin (MIC >32 mg/L). All facultative anaerobes were resistant to metronidazole (MIC > $128 \mathrm{mg} / \mathrm{L})$. E. coli was susceptible to gentamicin $(\mathrm{MIC}<0.5 \mathrm{mg} / \mathrm{L}$ ) and cefoxitin (MIC $2 \mathrm{mg} / \mathrm{L}) . S$. pyogenes was susceptible to spiramycin and cefoxitin $(\mathrm{MIC}<0.5 \mathrm{mg} / \mathrm{L})$.

\section{Antibiotic concentrations in serum}

The concentrations of antimicrobials were determined in animals challenged with $B$. fragilis and $B$. melaninogenicus. This was done to ascertain the level of antimicrobials achieved in an infected animal. The serum concentrations of metronidazole, spiramycin, and gentamicin were at least four times higher than the MIC for all susceptible bacteria (table I).

\section{Abscess formation}

Non-capsulate Bacteroides spp. did not induce abscesses when injected alone. All other test organisms caused abscesses when injected alone. The viable counts of each are noted in tables II and III. Abscesses usually were formed within $24-72 \mathrm{~h}$ of inoculation. When left alone, they reached a maximum diameter of 12-14 $\mathrm{mm}$ within 5-7 days, and began to drain between 10 and 20 days. As a consequence of mixed infections, the maximum diameter of an abscess was larger (22-24 $\mathrm{mm})$ than those caused by single organisms (12-15 $\mathrm{mm}$ ).

Histological examination of abscesses showed a central area of necrotic cells, fibrin, and bacteria, surrounded by a band of leucocytes and a distinct collagen capsule. There was no mortality associated with abscess formation.

Number of organisms in abscesses. The differences in the numbers of facultative and anaerobic bacteria found in untreated and treated animals were calculated. The differences in numbers $\left(\log _{10} \mathrm{cfu}\right)$ of facultative bacteria and the differences in numbers of Bacteroides spp. are presented in tables II and III.

The number of organisms in mixed infections of capsulate Bacteroides spp. and $S$. pyogenes or $E$. coli was always significantly larger than the number of each of the participating organisms in abscesses induced by a single species (tables II and III).

\section{Therapy of infections caused by single species}

Therapy with drugs to which the organisms were susceptible caused a significant decrease in the viable counts of all organisms. Metronidazole reduced the viable counts of the Bacteroides spp. and the sizes of the abscesses, spiramycin was effective against $S$. pyogenes, and gentamicin was active against $E$. coli. Cefoxitin was effective against all of the organisms. The combination of spiramycin and metronidazole reduced the viable count of $B$. melaninogenicus more than metronidazole alone. The combination of gentamicin and metronidazole showed no increased efficacy.

\section{Therapy of infections caused by two species}

Single therapy. Therapy with metronidazole was universally effective in reducing the viable counts of all non-capsulate and capsulate strains of $\boldsymbol{B}$. 


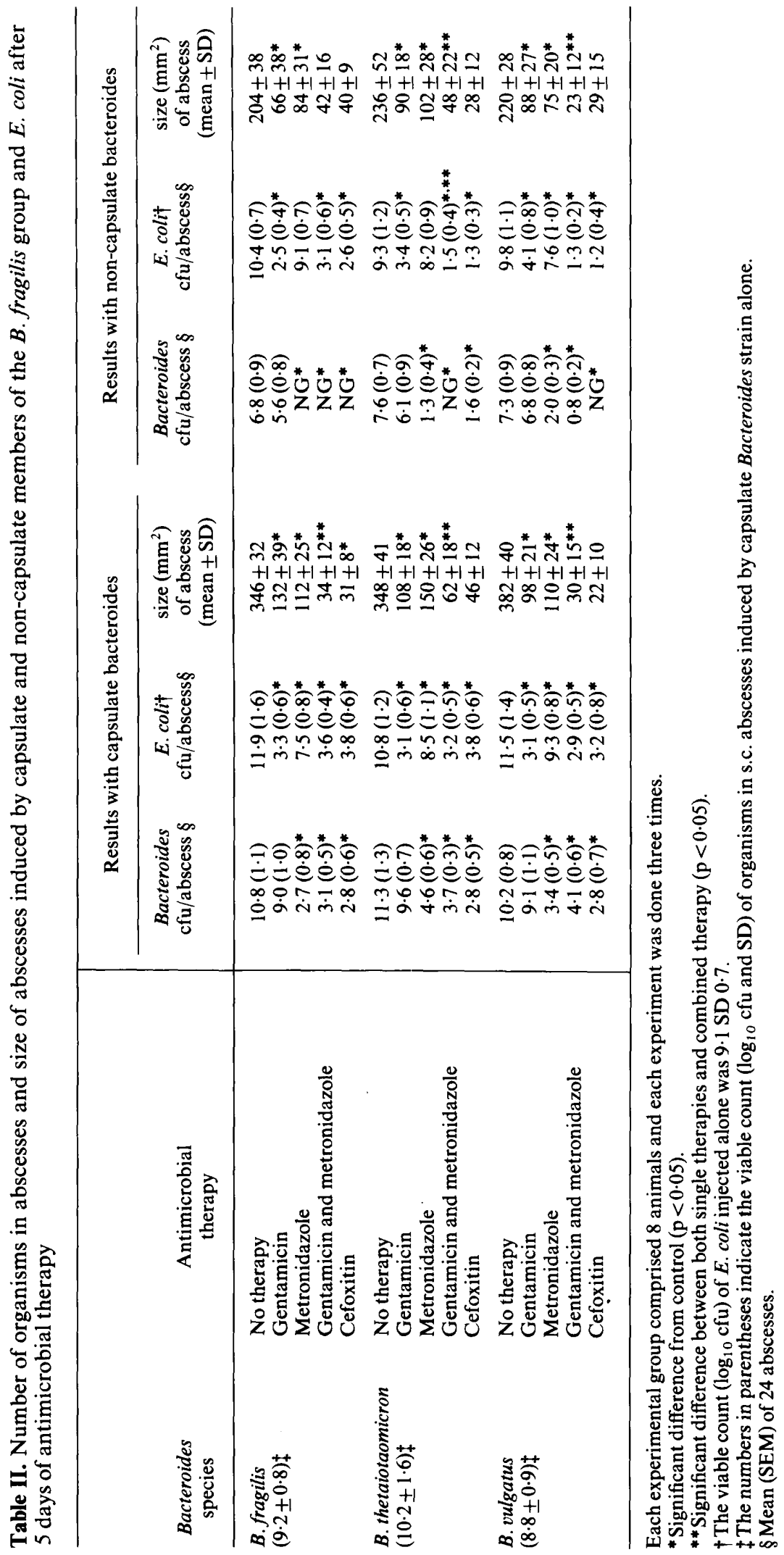




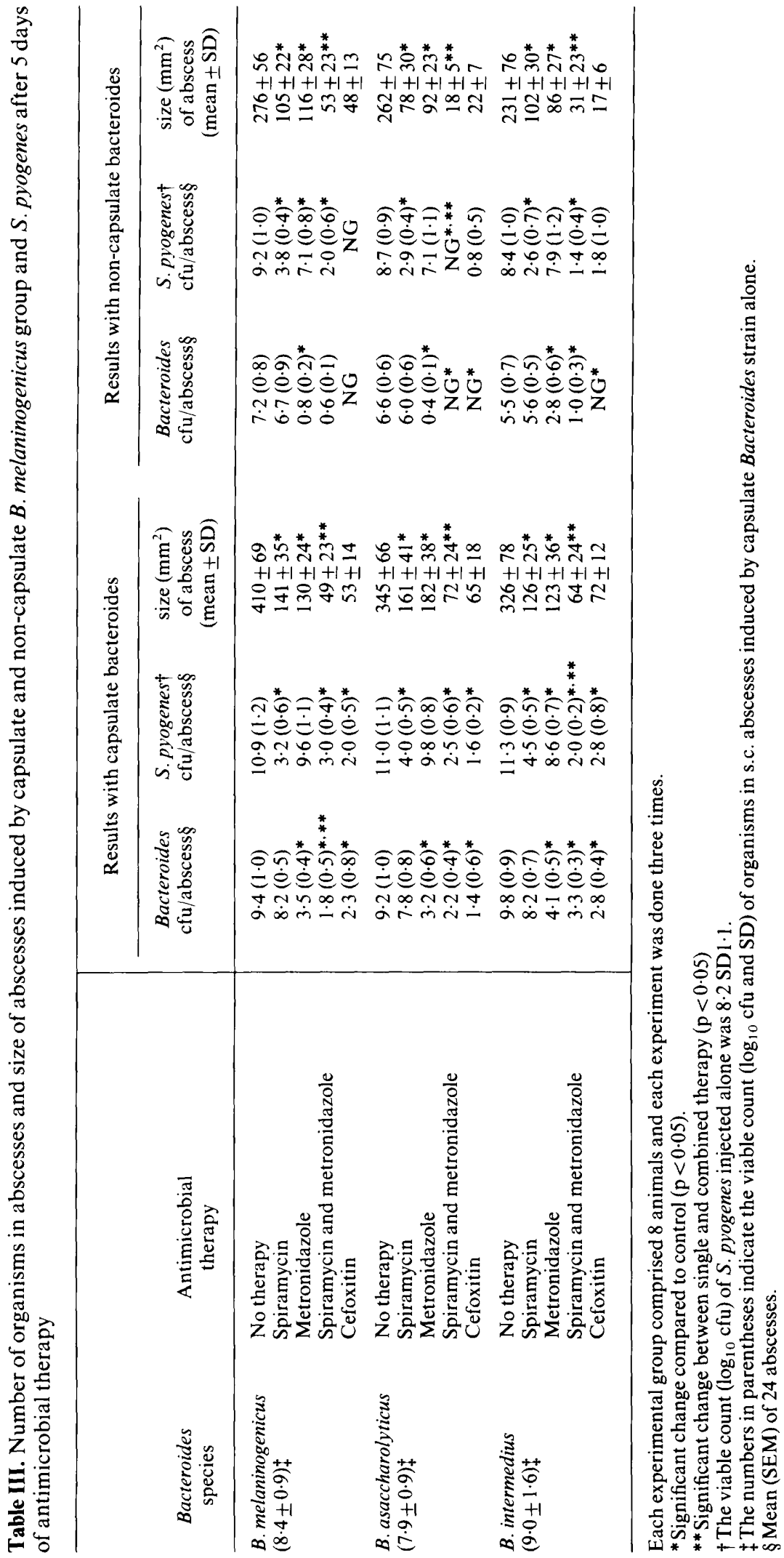


fragilis and B. melaninogenicus groups in all combinations. Spiramycin was effective in reducing the numbers of $S$. pyogenes, and gentamicin decreased the numbers of $E$. coli (tables II and III). Although the decrease in viable count of the susceptible organisms was the largest and occurred in all instances, the count of the other non-susceptible organisms was also reduced by a small but significant extent in 6 of the 24 combinations. Cefoxitin was as effective as combination therapy with gentamicin and metronidazole or spiramycin (see below).

Combination therapy. Combined therapy with gentamicin and metronidazole showed greater reduction of viable counts of $\boldsymbol{B}$. thetaiotaomicron, compared with reduction by either agent alone, when administered to animals with abscesses induced by non-capsulate $B$. thetaiotaomicron and $E$. coli (table II). Increased elimination of $S$. pyogenes was noted with the combination of spiramycin and metronidazole in mice with abscesses induced by capsulate $B$. intermedius and $S$. pyogenes (table III). Similarly, an increase in the eradication of $B$. melaninogenicus was noted in combined infections with $S$. pyogenes.

\section{Emergence of capsule}

Culturing of abscesses induced by non-capsulate Bacteroides spp. and S. pyogenes or E. coli revealed that the Bacteroides spp. became heavily capsulate (i.e., $>50 \%$ of cells showed the presence of capsule). This phenomenon occurred even in animals treated with antibiotics effective against $S$. pyogenes or $E$. coli, but not in those treated with metronidazole or cefoxitin, which are effective against the Bacteroides spp.

\section{Discussion}

The ability of members of the $B$. fragilis group, other than $B$. fragilis, to induce an abscess by themselves strengthens the evidence supporting their pathogenic role. $B$. fragilis is the most commonly isolated member of the $\boldsymbol{B}$. fragilis group, accounting for $40-50 \%$ (Brook, 1980; Sutter et al., 1985) of clinical isolates. However, the other members of the group account for the rest of the isolates and have frequently been isolated from blood cultures and other infected sites as the only isolates (Brook, 1988). Strains of $B$. thetaiotaomicron, $B$. vulgatus, and the $B$. melaninogenicus group possess capsular material that is morphologically similar to that of $B$. fragilis and all manifest the ability to express their capsule material after passage in an animal assisted by a "helper" organism (Brook et al., 1983, 1984). The inability of antimicrobial therapy directed at the eradication of the "helper" organism to prevent the emergence of the capsule and subsequent formation of a subcutaneous abscess strengthens the need to direct antimicrobial therapy at the eradication of both the aerobic and anaerobic components of mixed infections.

Although most members of the $\beta$. fragilis group possess the enzyme $\beta$-lactamase, and all are therefore resistant to penicillin, their susceptibility to cephalosporins varies (Tally et al., 1983). Of all the $B$. fragilis group, $B$. fragilis is the most susceptible to second- and third-generation cephalosporins (Wexler and Finegold, 1988). Among the secondand third-generation cephalosporins, cefoxitin is the most active against all members of the $B$. fragilis group (Tally et al., 1983; Wexler and Finegold, 1988). In this study, single-agent therapy with cefoxitin was shown to be as effective as combination therapies against single and combined infection. These data are supported by recent clinical studies in which therapy with cefoxitin was found to be equally effective as clindamycin plus an aminoglycoside (Gentry et al., 1984; Hofstetter et al., 1984; Nichols et al., 1984; Solomkin et al., 1984) and superior to cefamandole (Gentry et al., 1984; Jones et al., 1985) in the management of intraabdominal infection after trauma.

This study highlights the synergic relationship between the Bacteroides spp. and their aerobic and facultative counterparts in mixed infection. Such a relationship has been demonstrated in other studies, and it has been documented by increased mortality (Altemeier, 1942; Brook et al., 1984), abscess formation (Brook et al., 1983, 1984a, 1984b), and mutual enhancement of growth (Brook, 1985).

The interruption of such synergy by antimicrobial agents aimed at one component of the infection, the anaerobic or aerobic, had a significant effect on the untreated bacterial partner. This was especially apparent when therapy directed only at the facultative component (gentamicin or spiramycin) or the anaerobic component (metronidazole) was also effective in reducing the number of untreated bacteria. Despite this phenomenon, in no instance was such therapy effective in completely eliminating the infection and eradicating the untreated organisms, and the abscesses were still present.

The ability of metronidazole to reduce the viable counts of aerobes and facultative anaerobes when present in mixed infection with Bacteroides spp. could be due to its ability to reduce the numbers of the anaerobe, thus interfering with the synergic 
relationship between the two. A similar effect of metronidazole was previously noted in mixed infection with $B$. fragilis and $E$. coli (Onderdonk $e t$ al., 1979). They suggested that metabolites of metronidazole generated by $B$. fragilis impaired the viability of $E$. coli. Subsequently, Ingham et al. (1980) and Chrystal et al. (1980) demonstrated that, in anaerobic conditions, metronidazole temporarily reduces the number of $E$. coli. It seems, therefore, that metronidazole by itself may have direct antibacterial activity against $E$. coli in an anaerobic environment. Studies are warranted to further explore this phenomenon.

Our findings provide further support for the important pathogenic role of all members of the $B$. fragilis and $B$. melaninogenicus groups in mixed infections, and emphasise the need to use therapy directed at their eradication in the earlier stages of the infectious process. The advantages of eradicating non-capsulate Bacteroides spp. also reiterate the value of prophylactic therapy and specific therapy of mixed infection that includes coverage for the

\section{REFERENCES}

Aldridge K E, Sanders C V, Janney A, Faro S, Marier R L 1984 Comparison of activities of penicillin $G$ and new $\beta$-lactam antibiotics against clinical isolates of Bacteroides species. Antimicrobial Agents and Chemotherapy 26: 410-413.

Altemeier W A 1942 The pathogenicity of the bacteria of appendicitis peritonitis: experimental study Surgery 11: 374-384.

Brook I 1980 Bacterial studies of peritoneal cavity and postoperative surgical wound drainage following perforated appendix in children. Annals of Surgery 192: 208-212.

Brook I 1981 Anaerobic bacteria in pediatric respiratory infections: progress in diagnosis and treatment. Southern Medical Journal 74: 719-726.

Brook I 1985 Enhancement of growth of aerobic and facultative bacteria in mixed infections with Bacteroides species. Infection and Immunity 50: 929-931.

Brook I 1988 Recovery of anaerobic bacteria from clinical specimens in 12 years at two military hospitals. Journal of Clinical Microbiology 26: 1181-1188.

Brook I, Gilmore J D, Coolbaugh J C, Walker R I 1983 Pathogenicity of encapsulated Bacteroides melaninogenicus group, $B$. oralis and $B$. rumincola subsp. brevis in abscesses in mice. Journal of Infection 7: 218-226.

Brook I, Coolbaugh J C, Walker R I 1984a Pathogenicity of piliated and encapsulated Bacteroides fragilis. European Journal of Clinical Microbiology 3: 207-209.

Brook I, Hunter V, Walker R I 1984b Synergistic effect of Bacteroides, Clostridium, Fusobacterium, anaerobic cocci, and aerobic bacteria on mortality and induction of subcutaneous abscesses in mice. Journal of Infection 149: 924-928.

Chrystal E J T, Koch R L, McLafferty M A, Goldman P 1980 Relationship between metronidazole metabolism and bactericidal activity. Antimicrobial Agents and Chemotherapy 18: $566-573$.
Bacteroides spp. as well as its aerobic or facultative counterparts.

The importance of surgical drainage also is emphasised by this study because none of the antimicrobials or their combinations were effective in completely eradicating the infection. Therefore, surgical drainage supplemented by antimicrobials should be used in conjunction in the management of mixed infection.

I gratefully acknowledge the help of Mr J. E. Perry for technical assistance, Dr C. H. Dorsey for electronmicroscopy preparation, and Barbara Demusz for secretarial assistance.

The opinions and assertions contained herein are the private views of the writer and are not to be construed as official or reflecting the views of the Navy Department or the naval service at large.

The experiments reported herein were conducted according to the principles set forth in the "Guide for the Care and Use of Laboratory Animals" prepared by the Institute of Animal Resources, National Research Council, DHEW Pub. No. (NIH) 78-23.

Gentry L O, Feliciano D V, Scott A, Short H D, Matlox K L, Jordan G L 1984 Perioperative antibiotic therapy for penetrating injuries of the abdomen. Annals of Surgery 200: 561-566.

Hofstetter S R, Pachter H L, Bailey A A, Coppa G F 1984 A prospective comparison of two regimens of prophylactic antibiotics in abdominal trauma: cefoxitin versus triple drug. Journal of Trauma 24: 307-310.

Ingham H R, Hall C J, Sisson P R, Tharagonnet D, Selkon J B 1980 The activity of metronidazole against facultatively anaerobic bacteria. Journal of Antimicrobial Chemotherapy 6: $343-347$

Jones R C, Thal E R, Johnson N A, Gollihar L N 1985 Evaluation of antibiotic therapy following penetrating abdominal trauma. Annals of Surgery 201 : 576-585.

Kasper D L 1976 The polysaccharide capsule of Bacteroides fragilis subspecies fragilis: immunochemical and morphologic definition. Journal of Infectious Diseases 133: 79-87.

Lennette E H, Balows A, Hausler W, Shadomy H J (eds) 1985 Manual of Clinical Microbiology, 4th edn. American Society for Microbiology, Washington, DC.

Onderdonk A B, Kasper D L, Cisneros R I, Bartlett J B 1977 The capsular polysaccharide of Bacteroides fragilis as a virulence factor: comparison of pathogenic potential of encapsulated and unencapsulated strains. Journal of Infectious Diseases 136: 82-89.

Onderdonk A B, Louis T J, Tally F P, Bartlett J B 1979 Activity of metronidazole against Escherichia coli in experimental intra-abdominal sepsis. Journal of Antimicrobial Chemotherapy 5 : 201-210.

Nichols R L et al. 1984 Risk of infection after penetrating abdominal trauma. New England Journal of Medicine 311: $1065-1070$.

Solomkin J S, Meakins J L, Allo M D, Dellinger E P, Simmons R L 1984 Antibiotic trials in intra-abdominal infections: a critical evaluation of study design and outcome reporting. Annals of Surgery 200: 29-39. 
Sutter V L, Citron D M, Edelstein M A C, Finegold S M 1985 Wadsworth Anaerobic Bacteriology Manual, 4th edn. Star Publishing Company, Belmont, CA.

Tally F P et al. 1983 Susceptibility of Bacteroides fragilis group in the United States in 1981. Antimicrobial Agents and Chemotherapy 23 : 536-540.

Thornsberry C, Svenson J M 1978 Antimicrobial susceptibility testing of anaerobes. Laboratory Medicine 9: 43-48.
Wheeler L A, DeMeo M, Halula M, George L, Heseltine P 1978 Use of high-pressure liquid chromatography to determine plasma levels of metronidazole and metabolites after intravenous administration. Antimicrobial Agents and Chemotherapy 13: 205-209.

Wexler H M, Finegold S M 1988 In-vitro activity of cefoxitin compared with that of other antimicrobial agents against anaerobic bacteria. Antimicrobial Agents and Chemotherapy 22: 601-605. 